\title{
A Three-Parameter Model for Estimating Atmospheric Tritium Dose at the Savannah River Site
}

by

A. A. Simpkins

Westinghouse Savannah River Company

Savannah River Site

Aiken, South Carolina 29808

D. M. Hamby.

University of Michigan

MI USA

This paper was prepared in connection with work done under the above contract number with the U.S. Department of Energy. By acceptance of this paper, the publisher and/or recipient acknowledges the U.S. Government's right to retain a nonexclusive, royalty-free license in and to any copyright covering this paper, along with the right to reproduce and to authorize others to reproduce all or part of the copyrighted paper.

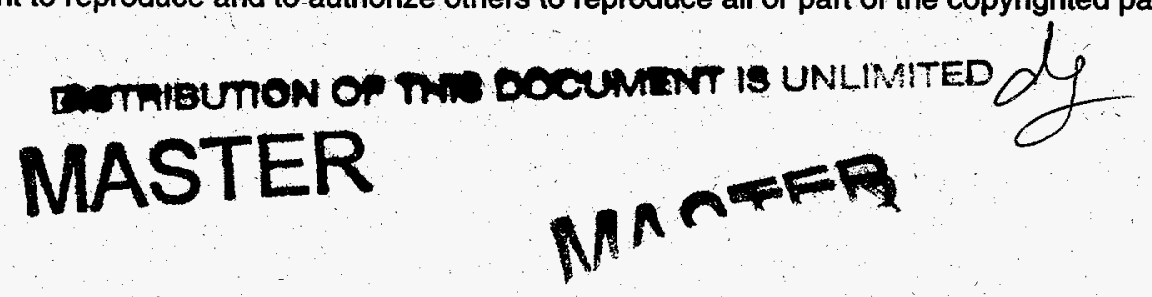




\section{DISCLAIMER}

This report was prepared as an account of work sponsored by an agency of the United States Government. Neither the United States Government nor any agency thereof, nor any of their employees, makes any warranty, express or implied, or assumes any legal liability or responsibility for the accuracy, completeness, or usefulness of any information, apparatus, product, or process disclosed, or represents that its use would not infringe privately owned rights. Reference herein to any specific commercial product, process, or service by trade name, trademark, manufacturer, or otherwise does not necessarily constitute or imply its endorsement, recommendation, or favoring by the United States Government or any agency thereof. The views and opinions of authors expressed herein do not necessarily state or reflect those of the United States Government or any agency thereof.

This report has been reproduced directly from the best available copy.

Available to DOE and DOE contractors from the Office of Scientific and Technical Information, P. O. Box 62, Oak Ridge, TN 37831; prices available from (423) 576-8401.

Available to the public from the National Technical Information Service, U. S. Department of Commerce, 5285 Port Royal Road, Springfield, VA 22161. 


\section{DISCLAIMER}

Portions of this document may be illegible electronic image products. Images are produced from the best available original document. 


\title{
A THREE-PARAMETER MODEL FOR ESTIMATING ATMOSPHERIC TRITIUM DOSE AT THE SAVANNAH RIVER SITE
}

\author{
D.M. Hamby \\ Environmental and Industrial Health \\ School of Public Health \\ University of Michigan \\ Ann Arbor, MI 48109-2029
}

\author{
A.A. Simpkins - \\ Environmental Analysis Section \\ Savannah River Technology Center \\ Westinghouse Savannah River Company \\ Aiken, SC 29808
}

\begin{abstract}
The models used in the NRC approach to assess chronic atmospheric releases of radioactivity generate deterministic dose estimates by using standard assumptions about exposure conditions and environmental transport mechanisms. This approach has been used at the Savannah River Site since 1983. Total dose to off-site maximum individuals at the SRS from atmospheric releases has been on the order of one microSeivert per year, three orders of magnitude lower than the 10CFR20 dose limit of $1 \mathrm{mSv} / \mathrm{yr}$ and two orders of magnitude lower than the NESHAP limit of $0.1 \mathrm{mSv} / \mathrm{yr}$. When estimating atmospheric dose many parameters remain unchanged each time environmental dose calculations are performed. These parameters, therefore, are essentially unimportant with regard to routine modeling. It is proposed, therefore, that transport and dosimetry models can be reduced to simple functions of a few parameters that essentially determine dose at all locations across the site. The three-parameter transport and dosimetry model developed in this work is useful for quick and easy estimates of chronic atmospheric tritium dose that are within a factor of 2 of estimates by more sophisticated models. The three parameters critical to estimating annual average concentration are wind-direction frequency, downwind distance, and stack height.. With slight modification, the proposed model should be applicable at other sites as long as terrestrial and atmospheric conditions are not vastly different than those found at the Savannah River Site. The model is bounded by physical stack heights between 10 and 61 meters and downwind distances between $800 \mathrm{~m}(0.5 \mathrm{mi}$.) and $32 \mathrm{~km}$ (20 mi.). It requires knowledge of wind-direction frequency, downwind distance, and physical stack height to estimate an Atmospheric Dose Factor (ADF; in units of mrem/Ci) for the conversion of long-term release activity to maximum individual effective dose equivalent. This concept is being carried forward to the development of a reduced model for particulate emissions from SRS stacks.
\end{abstract}

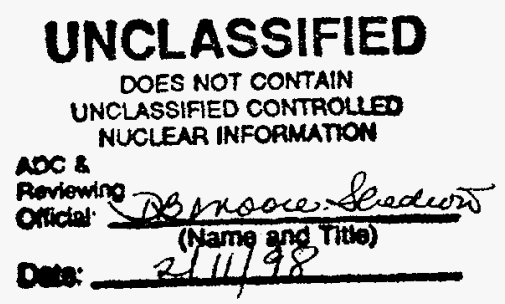




\section{A THREE-PARAMETER MODEL FOR ESTIMATING ATMOSPHERIC TRITIUMI DOSE AT THE SAVANNAH RIVER SITE}

\section{INTRODUCTION}

Doses to uniquely defined off-site individuals are routinely reported for chronic atmospheric releases of radioactivity from nuclear installations in the United States. Such dose estimates are generally produced pursuant to the methodology prescribed by the US Nuclear Regulatory Commission (NRC). The models used in the NRC approach generate deterministic dose estimates by using standardized and often simplified assumptions about exposure conditions and environmental transport mechanisms as input to a series of calculational routines (NRC 1977a, 1977b). This approach has been used at the Savannah River Site (SRS) since 1983 in the form of site-specific versions of computer codes employing the NRC models.

Since 1991, with the cessation of weapons-materials production, total dose to off-site maximum individuals at the SRS from atmospheric releases has been on the order of one microSeivert per year, three orders of magnitude lower than the 10CFR20 dose limit of $1 \mathrm{mSv} / \mathrm{yr}$ and two orders of magnitude lower than the NESHAP limit of $0.1 \mathrm{mSv} / \mathrm{yr}$. In years prior to 1991, typical doses were on the order of tens of $\mu \mathrm{Sv} / \mathrm{yr}$, still much lower than the exposure limit. Tritium oxide released to the atmosphere from the SRS accounts for a large fraction of off-site dose. Previous work (Hamby 1993) shows that the uncertainty in the calculation of individual dose from atmospheric tritium, starting with a "known" atmospheric concentration, spans more than an order of magnitude. Additionally, long-term air concentration estimates of tritium oxide over-predict actual concentrations at the SRS by as much as a factor of two (Simpkins and Hamby 1997) and long-term atmospheric concentration estimates, in general, are within a factor of 2 to 4 for noncomplex terrain (Miller and Hively 1987).

When estimating atmospheric dose at the SRS, as would be the case at other sites, many parameters remain unchanged each time environmental dose calculations are performed. These parameters, therefore, are essentially unimportant with regard to routine modeling, even if they are ones to which the model is sensitive (Hamby 1995). Transport and dosimetry models can, therefore, be reduced to simple functions by determining which parameters change from one calculation to the next, resulting in a few parameters that essentially determine dose at all locations across the site. 
Screening models are in use around the country as a way of quickly determining compliance status or order-of-magnitude consequence for various release scenarios (US EPA 1992; NCRP 1996). Although greatly simplified, these models still require the use of a desktop computer or rather laborious hand-calculations. With uncertainties in tritium dose predictions spanning more than an order of magnitude (Hamby 1993), and with environmental doses at SRS being much less than allowable limits, use of a simplified model, one that can be executed on a hand calculator, is justified in terms of cost, time and resource savings as long as its results are comparable to those from standard methods.

\section{TRITIUM TRANSPORT AND DOSE MODELING}

The transport of tritium from its release through the atmosphere to human receptors is typically predicted using a Gaussian plume model (NRC 1977b) to estimate downwind air concentrations and a specific activity model (NRC 1977a) to estimate concentrations in various environmental media. The generalized Gaussian model,

$$
\chi=\frac{Q}{\pi \sigma_{y} \sigma_{z} u} \cdot e^{-\frac{y^{2}}{2 \sigma_{y}^{2}}} \cdot e^{-\frac{\left(h_{s}\right)^{2}}{2 \sigma_{z}^{2}}}
$$

is used to estimate downwind, ground-level concentrations for short-duration releases. Descriptions of the parameters in Eqn. 1 and in equations to follow are given in Table 1. For longer time frames, over periods where wind characteristics (speed, stability, and direction) are expected to vary, a sector-averaged concentration is predicted where,

$$
\chi_{\text {sector_avg }}=\frac{6.385 Q}{\pi x \sigma_{2} u} e^{-\frac{\left(h_{s}\right)^{2}}{2 \sigma_{z}^{2}}}
$$

An array of sector-averaged concentrations is calculated for all combinations of wind speed category, $i$, and stability class, $j$. These concentrations are then multiplied by their respective frequency of occurrence, $f_{i j}$, summed, and multiplied by the frequency with which winds blow toward sector $k$, such that,

$$
\chi_{\text {annual_avg }}=f_{k} \sum_{i j} \frac{2.032 Q f_{i j}}{x\left(\sigma_{z}\right)_{i j} u_{i j}} e^{-\frac{\left(h_{i}\right)^{2}}{2\left(\sigma_{z}\right)_{i j}^{2}}},
$$


the formulation for estimating annual-average air concentration. Using a specific activity model, the concentration of tritium in vegetation, $\mathrm{C}_{\mathrm{v}}$, is modeled as,

$$
C_{V}=\frac{\chi \cdot f_{w} \cdot R_{p a}}{H},
$$

where $f_{w}$ is the fraction of plant mass that is water, $R_{p a}$ is the ratio of plant tritium (in the oxide form) to atmospheric tritium (Hamby and Bauer 1994), and $\mathrm{H}$ is the absolute humidity. The: concentration of tritium in beef (or milk), $\mathrm{C}_{\mathrm{M}}$, is determined by,

$$
C_{M}=C_{V} F_{m} Q_{F} e^{-\lambda t_{t}},
$$

where $F_{m}$ is the feed-to-meat (or milk) transfer coefficient, $Q_{F}$ is the consumption rate for beef (or: milk) cattle, $\lambda$ is the radiological decay constant, and $t_{t}$ is the transport time of beef (or milk) from the farm to the point of sale. Since the half-life of tritium is more than twelve years, and the transport times for beef and milk are on the order of a few days, the exponential term in Eqn. 5 is essentially equal to unity.

Once concentrations are determined for the various environmental media, $\mathrm{C}_{\mathrm{EM}}$, doses are estimated using the general equation:

$$
\text { Dose }=C_{E M} \cdot U \cdot D F \cdot t \text {, }
$$

where $U$ represents the usage factor or consumption rate for a given consumable or exposure condition, DF is the internal tritium dose factor (DOE 1988; EPA 1988), and $t$ is "the time of exposure (generally, one year). Exposure pathways for tritium considered at the SRS include inhalation, skin absorption (taken to be 50\% of the intake from inhalation (ICRP 1978)), ingestion of leafy and non-leafy vegetables, ingestion of beef, and ingestion of milk.

By combining Eqns. 3 through 6 we can develop an aggregated transport and dosimetry model for atmospheric tritium. Dose to an individual at a distance, $x$, from the release point for a particular windspeed and stability is, 


$$
\begin{aligned}
D_{i j}(x)=\left\{\frac{2.032 Q f_{w} R_{p a} D F}{\left(\sigma_{z}\right)_{i j} u_{i j} x H} e^{\left.-\frac{h_{c}^{2}}{2\left(\sigma_{z}\right)_{i j}^{2}}\right\}}\right. & \\
& *\left\{\left(\frac{1.5(B R) H}{f_{w} R_{p a}}\right)+\left(U_{b} f_{b} I R_{b} e^{-\lambda t_{b}}\right)+\left(U_{m} f_{m} I R_{m} e^{-\lambda_{m}}\right)+\left(U_{v} f_{v}\right)+\left(U_{l v} f_{l v}\right)\right\},
\end{aligned}
$$

a combination of the NRC's atmospheric dispersion model (1977b) and the NRC's atmospheric tritium dose model (1977a). The five terms in the second set of brackets represent the exposure pathways of inhalation/skin absorption, beef consumption, milk consumption, non-leafy vegetable consumption, and leafy vegetable consumption, respectively. The aggregated model is useful in facilitating sensitivity analysis (Hamby 1995) and is paramount in deriving our simplified threeparameter model.

The model of Eqn. 7 is the same, except for slight modification as described below, as that used on a routine basis at the SRS. The MAXIGASP code (Bauer 1991; Hamby 1992; Simpkins and Hamby 1997) is a site-specific combination of a module to calculate atmospheric concentrations, XOQDOQ by Sagendorf et al. (1982), and a module to estimate internal and external dose, GASPAR by Eckerman et al. (1980).

Given a joint frequency distribution (JFD) of wind speed and stability for a given wind direction, annual dose to a downwind individual is determined by,

$$
D_{k}(x)=f_{k} \cdot \sum_{i j} D_{i j}(x) \cdot f_{i j}
$$

For calculations of $D_{i j}(x)$, at a given downwind distance and in a particular sector, only the parameters $\left(\sigma_{z}\right)_{i j}$ and $u_{i j}$ will take on different values. Therefore, using average values of $\left(\sigma_{z}\right)_{i j}$ and $u_{i j}$, weighted by the JFD, Eqns. 7 and 8 can be combined such that,

$$
\begin{aligned}
D_{k}(x)=\left[\frac{2.032 Q f_{k} f_{w} R_{p a} D F}{\left(\sigma_{z}\right)_{k} u_{k} x H} e^{-\frac{h_{i}^{2}}{2\left(\sigma_{z}\right)^{2}}}\right] & \\
& *\left\{\left(\frac{1.5(B R) H}{f_{w} R_{p a}}\right)+\left(U_{m} f_{m} I R_{m} e^{-\lambda f_{m}}\right)+\left(U_{m} f_{m} I R_{m} e^{-\lambda_{m}}\right)+\left(U_{v} f_{v}\right)+\left(U_{l v} f_{l v}\right)\right\},
\end{aligned}
$$


where $\left(\sigma_{z}\right)_{k}$ and $u_{k}$ are the sector-averaged vertical diffusion coefficient and windspeed, respectively.

In the equations above, the effective release height, $h_{e}$, takes into account the physical height of the stack, any plume rise component, and any increase in elevation between the release point and the receptor. Atmospheric modeling for environmental dosimetry at SRS is carried out with the conservative assumption of no plume rise, however, changes in elevation are considered. One of the goals of developing our reduced model is computational ease, including parameterization and the ease in which input values are obtained. Effective stack height is most easily modeled ats simply the stack's physical height. Since the SRS terrain is relatively flat, with a gentle upward slope from the southwest to the northeast, the error contributed to the output from a simplified model as a result of assuming flat terrain is expected to be minimal.

Other potential sources of inaccuracies in our simplified or reduced model are borne out of the handling of wind speed as a function of elevation above the ground surface and constraints placed on the maximum value of the vertical diffusion coefficient. During each calculation of dose using the full model (Eqn. 7), wind speed is corrected for release height using the power function,

$$
F=\left(h_{e} / h_{m}\right)^{C E_{j}},
$$

where $h_{e}$ is the effective release height, $h_{m}$ is the height of wind-speed measurements, and the ratio of the two is raised to the $\mathrm{CE}_{\mathrm{j}}$ power, the value of which depends on atmospheric stability (Pendergast 1976; Stull 1988). In the full model used at the SRS, the value of $C_{\mathrm{j}}$ is 0.25 for stability classes A through D, and 0.5 for classes E, F, and G. The corrected wind speed is then the product of the measured wind speed and the factor, F. According to this model, the maximum change in wind speed occurs when the value of $F$ is at its minimum. This occurs when the atmosphere is stable and when the release height is at its lowest (i.e., 10 meters for applicability with the reduced model). Wind statistics used for modeling at the SRS are measured at a height of 61 meters. Under the stated conditions, wind speed at lower altitudes is reduced by as much as $60 \%$, resulting in an increase in the modeled concentration for a given set of atmospheric conditions of as much as 2.5 times. This increase, however, is for calculations of downwind concentration under specific atmospheric conditions, thus the impact on the model presented below is expected to be reduced considerably due to the averaging effects of calculating an annual-average concentration. 
The annual-averaged value of inversion height at the Savannah River Site is approximately 1000 meters. Therefore, when calculating the atmospheric concentration of various nuclides, based on the 5-year JFD, the values of $\sigma_{\mathrm{z}}$ are constrained to be no greater than the average lid height. There is no impact on these calculations for conditions of a neutral or stable atmosphere. However, during times of instability, values of $\sigma_{z}$ can become quite large unless constrained. The impact that this will have on how accurately the reduced model can estimate dose relative to the full model is assumed to be minor, given that the model is essentially estimating a weighted average stability over an entire year.

\section{DEVELOPMENT OF A REDUCED MODEL}

Least Squares Method and Model-Selection Criteria. A least-squares minimization technique was used to develop parameter coefficients in the reduced model by comparing fullmodel (Eqn. 7) dose calculational results with the reduced-model predictions. One hundred eleven input data points were employed as release scenarios in multiple iterations to systematically adjust parameter coefficients, thereby reducing the sum of the squared residuals between full- and reduced-model predictions.

More than twenty variants of the reduced model (to be described below) were analyzed and compared in selecting the preferred model. The criteria developed for model comparison included quantitative measures of model accuracy and precision, and a qualitative assessment of calculational ease.

The sum of squared fractional differences was used to measure model accuracy; i.e., the fit of the reduced-model results, as determined by the iterative method, to the associated full-model output. It is also the measure that is minimized in the least-squares technique. Our quantitative measure of model accuracy, $\mathbf{M}_{\mathbf{a}}$, is essentially the chi-square statistic and is represented here as,

$$
M_{a}=\sum_{i} \delta_{i}^{2},
$$

where $\delta_{\mathrm{i}}$ is the fractional difference or sometimes referred to as the residual,

$$
\delta_{i}=\frac{D_{i f}-D_{i r}}{D_{i f}},
$$


and $\mathrm{D}_{\mathrm{ir}}$ is the full-model dose prediction (the "expected" value) and $\mathrm{D}_{\mathrm{ir}}$ is the reduced-model dose prediction (the "observed" value). This measure gives a relative comparison of how closely the data can be fit to a single function for each model variant. Fractional or relative differences in the full- and reduced-model predictions, i.e., relative to the full-model predicted dose, are used in this measure since the dose estimates span several orders of magnitude; using absolute differences would result in more weight being given to the datasets producing dose predictions of larger magnitude.

Relative precision of reduced-model variants are measured by the standard deviation of the fractional differences of the reduced- and full-model predictions. Algebraically, our measure of precision, $\mathrm{M}_{\mathrm{p}}$, is,

$$
M_{p}=\sqrt{\frac{\sum_{i=1}^{n}\left(\delta_{i}-\bar{\delta}\right)^{2}}{n-1}},
$$

and is essentially the standard deviation of residuals, with $\bar{\delta}$ equal to the average of the n residual values of $\delta_{\mathrm{i}}$.

The minimum and maximum, values of $\delta_{i}$ over the 111 datasets analyzed were used as additional qualitative measures of both precision and accuracy. Relative precision was determined from these values by noting the range between the minimum and maximum values and relative accuracy was determined by how close the midpoint of the range was to zero.

Calculational ease was also a factor in selecting the preferred model. Several model variants gave similar results without appreciably compromising accuracy or precision. Therefore, the selected model was one that did not necessarily produce the best accuracy/precision measures, but its predictions were judged to be comparable to the predictions of the most accurate model variant, yet with a requirement of less calculational rigor.

The Reduced Model. Of all the potential radiological emission points at the Savannah River Site, more than $98 \%$ of the atmospheric tritium oxide is released from the reactor and separations facilities, with an additional 1\% originating from the heavy water treatment facility (SRS 1997). Other origination points do exist, however, but include various unmonitored diffuse and fugitive 
sources around the site. In the vast majority of instances, tritium that is released to the atmosphere will be purged through a given facility's exhaust stack as opposed to a building vent. At the SRS, these stacks are typically between 10 and 61 meters, with the preponderance of releases exhausted from the 61 meter stacks. Additionally, environmental dose calculations are carried out for individuals residing at the site boundary, i.e., at downwind distances from $800 \mathrm{~m}(0.5 \mathrm{mi})$ to about $32 \mathrm{~km}$ ( $20 \mathrm{mi}$.), depending on the release location. The reduced model developed here, therefore, is bounded in its applicability by these features.

Parameters that are important in the reduced model, in the context of this paper, are those that change from one calculation to the next when estimating downwind dose due to atmospheric releases of tritium oxide. The important parameters, therefore, in Eqn. 9 are $Q, f_{k}, h_{e},\left(\sigma_{z}\right)_{k}, u_{k}$, and $\mathrm{x}$. All other parameters are assumed constant for all annually-averaged calculations of atmospheric tritium dose at any location within $80 \mathrm{~km}(50 \mathrm{mi}$.) of the SRS.

The reduced model is formulated, first, on the premise that dose can be estimated by substituting all parameters that remain unchanged for any calculation of atmospheric tritium dose at the SRS with a single proportionality constant, K. Therefore, Eqn. 9 can be represented as,

$$
D_{k}(x)=\frac{K f_{k} Q}{\left(\sigma_{z}\right)_{k} u_{k} x} e^{-\frac{h_{k}^{2}}{2\left(\sigma_{z}\right)_{k}^{2}}}
$$

Since the release rate, $Q$, is the total tritium activity, $A_{T}$, released per unit time, $t$ (one year in this case), the constant of time also can be absorbed into $K$. And, if we approximate $\left(\sigma_{z}\right)_{k}$ with the power function, $A x^{B}+C$ (Eimutis and Konieck 1972), and make the assumption that $\left(\sigma_{z}\right)_{k}$ as a function of distance will not vary appreciably from one sector to the next, then

$$
\frac{D}{A_{T}}=\frac{K f_{k}}{\left(A x^{B+1}+C x\right) u_{k}} e^{-\frac{h_{c}^{2}}{2\left(A x^{B}+C\right)^{2}}}
$$

When estimating the value of $\left(\sigma_{z}\right)_{k}$ using the power function, the constants, $A, B$, and $C$, will take on different values based on stability category. However, when estimating annual average concentration at a given location, we are assuming that $\left(\sigma_{z}\right)_{k}$ can be represented with a JFDweighted average value of the vertical diffusion coefficient. Therefore, single values of $A, B$, and $\mathrm{C}$ will be used to calculate that average value. 
The ratio, D/A , will be called the "Atmospheric Dose Factor" (ADF) and will be in units of dose (in mrem) per unit activity (in curies) of tritium released to the atmosphere. It is Eqn. 15 that is considered here as the fundamental reduced model. A number of variations of the fundamental model were assessed in attempting to simplify the function, yet maintain predictability of atmospheric tritium dose. Variations of Eqn. 15 include, but are not limited to, those shown in Table 2.

The greatest simplification of the fundamental model would be the removal of the exponential term which accounts for stack height and its influence with regard to vertical stability. Considering an average value of $\sigma_{z}$, weighted by the JFD and substituted with the power function, the exponent,

$$
e^{-\frac{h_{c}^{2}}{2\left(A x^{3}+C\right)^{2}}}
$$

is more important at close distances as stack height increases (within about 5000 meters). At greater distances, for the range of possible stack heights at SRS, the exponential is essentially equal to unity (see Fig. 1). The two parameters determining the value of the exponent are downwind distance and stack height. Compensation for distance will be handled in the denominator of the model's other term, whereas stack height must be considered separately.

The power term in the denominator of Eqn. $15, \mathrm{~B}+1$, will be replace with $\mathrm{B}$, since it is simply a coefficient to be determined by the least-squares minimization technique. And, since downwind concentration at a given location, again with an estimate of average vertical stability, is inversely related to stack height, the first model variant considered was,

$$
A D F=\frac{K f_{k}}{\left(A x^{B}+C x\right) u_{k} h_{s}}
$$

where the $\mathrm{ADF}$ is considered to be directly proportional to the inverse of stack height. Predictability of dose using this model is lessened compared to the fundamental model (see Table 2). In Fig. 1, the curves of inverse stack height and inverse natural log of stack height have been normalized to a value of one at a stack height of 10 meters. This allows these functions to be compared to the value of the exponent for values of stack height from 10 to 61 meters. From Fig. 1 , it is apparent that the normalized function of inverse stack height does not represent the value of the exponent. However, the figure shows that the normalized function of inverse natural logarithm of stack height may be more appropriate. Therefore, another variant of the reduced model, 


$$
A D F=\frac{K f_{k}}{\left(A x^{B}+C x\right) u_{k} \ln \left(h_{s}\right)},
$$

was considered and shown to be a better predictor with even more precision than the fundamental model of Eqn. 15.

Since a site-averaged windspeed, $u_{t}$, is more easily managed than individual sector-specific windspeeds, the reduced model was then tested by replacing $u_{k}$ with $u_{t}$. The resultant model variant,

$$
A D F=\frac{K f_{k}}{\left(A x^{B}+C x\right) u_{t} \ln \left(h_{s}\right)},
$$

showed an appreciable increase in both accuracy and precision. Additionally, when windspeed was removed from the model all-together, making it even simpler,

$$
A D F=\frac{K f_{k}}{\left(A x^{B}+C x\right) \ln \left(h_{s}\right)},
$$

"predictability was unchanged. Solèly in the interest of simplification, the term $\mathrm{Cx}$ in the denominator was removed, the constant $\mathrm{A}$ was joined with the constant $\mathrm{K}$ and, again, the model was tested. The minimization technique showed that model accuracy and precision was compromised, but not to a degree that would prohibit its use in the form,

$$
A D F=\frac{K f}{x^{B} \cdot \ln \left(h_{s}\right)} .
$$

The final three-parameter model, Eqn. 21, was evaluated using the iterative method described and its resultant values of the constants were as follows: $K=17.5$ and $B=1.36$; so that the $A D F$ is equal to:

$$
A D F=\frac{17.5 f}{x^{1.36} \cdot \ln \left(h_{s}\right)}
$$


Atmospheric tritium dose to the receptor is then estimated from the reduced model by,

$$
D_{r}[m r e m]=A D F\left[\frac{m r e m}{C i}\right] \cdot A_{T}[C i],
$$

where $D_{r}$ is the chronic dose to a maximum individual at a given downwind distance as a result of the release of an amount, $\mathrm{A}_{\mathrm{T}}$, of atmospheric tritium over the course of an "extended period". This period can be any length of time as long as equilibrium is established between atmospheric and vegetation tritium and between vegetation and animal tritium. Additionally, the time must be such that the meteorological conditions are well described by the joint frequency distribution(s) used in its development. The intent of the $\mathrm{ADF}$ is, however, meant to be applied to annual dose estimates.

Although there is no prevailing wind at the SRS, meteorological data show that average annual wind-direction frequencies range from roughly 3 to $9 \%$ over the sixteen cardinal sectors. Therefore, the parameter, $\mathrm{f}$, is very important in the reduced model because of the potential threefold difference in the value of the parameter. Likewise, stack height and downwind distance are critical in the estimation of atmospheric concentration, and thus environmental dose.

Variability in the difference between the reduced- and full-model predictions is present since the reduced model is used to predict environmental dose over all sectors where the frequency of windspeed and stability are known to change. However, by using a power function to approximate a weighted average of $\sigma_{z}$, in terms of downwind distance, the reduced model is capable of dose estimates that are comparable, and certainly within the realm of uncertainty, to predictions using current models.

In addition to the model variants addressed above, and shown in Table 2, several other models were examined to determine the influence of terrain and various windspeed measures. These studies suggest that the $\mathrm{ADF}$ is not sensitive to elevation increases for a relatively flat site, such as the SRS, and that windspeed, when averaged over an entire year, is simply not important in predicting dose within reasonable limits. The results, therefore, indicate that the three-parameters of Eqn. 22 are sufficient to estimate downwind atmospheric tritium dose to within a factor of 2 of doses calculated with the full NRC atmospheric and dosimetry models (i.e., Eqn. 7). 


\section{ANALYSIS OF THREE-PARAMETER MODEL}

The final three-parameter model, Eqn. 22, was assessed by examining scatter plots of the squared fractional difference, $\delta^{2}$, as a function of several potentially influential parameters. The intent of this analysis was to uncover systematic errors that would not be noticeable otherwise, so that global corrections could be made to the model, if necessary.

Figure 2 is a logarithmic plot of the reduced-model predicted dose (the three-parameter model) versus full-model predicted dose (the NRC models) for the dataset of 111 inputs considering a one-curie release of tritium. The plot exhibits excellent agreement over the full range of dose values, in this case three orders of magnitude. The solid line in the figure is not a regression curve, but given is to indicate a slope of one. There appears to be a slight tendency for overprediction at low dose $\left(10^{-7} \mathrm{mrem} / \mathrm{Ci}\right)$ and under-prediction at high dose $\left(10^{-4} \mathrm{mrem} / \mathrm{Ci}\right)$, but only for a few estimates at the ends of the dose range.

The histogram of Fig. 3 shows the distribution of fractional difference, $\delta$, for the data in Fig. 2 , but with the parameter $\mathrm{K}$ equal to 15.8 , the original value of the constant that resulted in the lowest sum of residuals. The frequency of negative values outweighs the frequency of positive values, indicating that the model is more likely to under-predict full-model dose. To correct this problem, the value of the constant, $\mathrm{K}$, in Eqn. 22, was increased to 17.5. This increase results in a higher residual, however, the distribution of under- and over-predictions is more balanced (see Fig. 4). Figure 4 appears to be skewed such that the positive fractional differences are of greater magnitude than the negative fractional differences. By definition, however, a positive value of 0.5 for fractional difference indicates that $D_{r}$ is a factor of 1.5 times higher than $D_{f}$, whereas a value of -0.5 indicates that $D_{r}$ is less than $D_{f}$ by a factor of 2.0. The extreme limits of the fractional difference in Fig. 4, therefore, show that the reduced model may overestimate the full model by-as much as a factor of 2.1 and may underestimate the full model by as much as a factor of 1.7. The over- and under-predictions, however, continue to remain well within the realm of uncertainty of tritium transport and dosimetry estimates and are adequate for screening measures.

The data points that result in the largest positive fractional differences generally are those associated with very low frequencies of occurrence. For instance, the four highest values are associated with different stack heights and varying receptor distances, but the frequencies of occurrence for each scenario are of the lowest values in the overall dataset, approximately $2.5 \%$. At the other end of Fig. 4 , the four smallest values of fractional difference appear to be related, not necessarily to 
wind-direction frequency, but more so to a combination of shorter stack height and close-in receptor distances.

Figures 5 through 8 are scatter plots of the squared fractional differences, $\delta^{2}$, versus downwind distance, wind-direction frequency, physical stack height, and windspeed, respectively. These plots give an indication of how well various parameters fit the model. Figure 5 suggests that downwind distance is not systematically influencing reduced-model results. However, as mentioned above, the distribution of $\delta^{2}$ as a function of directional frequency for the reduced model (Fig. 6) shows a slight systematic dependency of error on wind-direction frequency in that the three largest residuals occur for scenarios where the value of $f$ is at its minimum.

The influence of stack height on $\delta^{2}$ is plotted in Fig. 7. Interestingly, there is one data point in each of the stack-height categories that is dramatically different than the rest. The outlying residual value for each stack height is associated with the lowest values of wind-direction frequency, corresponding to winds blowing to the south. On closer examination of the joint frequency distributions for the various meteorological towers located on the SRS, it is apparent that when the wind blows to the south, there is a preponderance of conditions resulting in an extremely unstable atmosphere. The frequency of A stability, for example, in other sectors is roughly equal to $20 \%$, whereas for the south sector of each of the databases, the frequency of A stability conditions is about $60 \%$, a three-fold increase over other sectors. So, not only does the wind rarely blow to the south, but it is consistently unstable when doing so. Since the vertical diffusion coefficient, represented as the power function in the reduced model, is in the denominator, smaller values result in higher doses. Since the reduced model is essentially using an average stability, something similar to neutral conditions, it is overestimating dose in the south sector because those winds are predominantly unstable.

Even though windspeed is not considered in the three-parameter model, its influence on model variability was examined as an additional determinant of its importance. The distribution of $\delta^{2}$ as a function of windspeed is given in Fig. 8. Consistent with the finding that windspeed was not a reasonably important factor, the figure suggests that windspeed does not systematically affect reduced-model results.

\section{DISCUSSION}

The three-parameter transport and dosimetry model is useful for quick and easy estimates of chronic atmospheric tritium dose that are within a factor of 2 of estimates by more sophisticated 
models. When examining the aggregate of the tritium transport and dosimetry models (Eqn. 7), we see that, for a given site, there are very few parameter values that change from one calculation to the next. In fact, the only parameters that change are those that deal with atmospheric transport. Thereafter, dose predictions are directly proportional to air concentration. The three parameters critical to estimating annual average concentration are those in the final reduced model, winddirection frequency, downwind distance, and stack height.

With slight modification, the model proposed here should be applicable at other sites as long as terrain is relatively flat and non-complex, e.g., not in a river valley or in mountainous terrain, such that weighted-average values of windspeed and vertical stability are not vastly different than those found at the Savannah River Site. The model as presented is specific to the SRS, but it may be possible to include site-averaged windspeed, for example, as a normalizing factor between sites so that it's applicability could be broadened. Values of the coefficients, $\mathrm{K}$ and $\mathrm{B}$, would have to be determined based on site-specific scenarios, but otherwise the basic form of the reduced model should be appropriate.

As indicated by Figs. 3 and 4, the model's relative number of over- and under-estimates can be altered by changing the value of the constant, $\mathrm{K}$. For example, if it is desirable that the model rarely under-predicts, then the value of $K$ could be increased accordingly. By increasing $K$, the values of reduced-model predicted dose in Fig. 2 increase proportionally for the range of doses. Modifications to the value of $B$ in the reduced model also, of course, will alter the reduced-model results. Because it is in the denominator, an increase in $B$ results in a decrease in the model predictions. However, since it is in the power term, a change in B also affects the slope of the predicted-to-observed dose values.

Based on the chi-square calculations, the fit of predicted doses from the reduced model ("observed" values) to those of the full model ("predicted" values) are in excellent agreement for all reduced-model variants (see Table 2). With 30 degrees of freedom and at a significance level of $0.1 \%$, the chi-square critical value is 59.7 (Box et al. 1978). Since we have 110 degrees of freedom, the critical value for comparability in this work is, therefore, something greater than that for 30 degrees of freedom. As seen in Table 2, our chi-square values are between 9 and 15 for the model variants shown. 


\section{CONCLUSION}

We have developed a three-parameter model to predict chronic atmospheric tritium dose resulting from stack releases at the Savannah River Site. The model is bounded by physical stack heights between 10 and 61 meters and downwind distances between $800 \mathrm{~m}$ and $32 \mathrm{~km}$. It requires knowledge of wind-direction frequency, downwind distance, and physical stack height to estimate an Atmospheric Dose Factor ( $\mathrm{ADF}$; in units of mrem/Ci) for the conversion of long-term release activity to maximum individual effective dose equivalent. The reduced model,

$$
A D F=\frac{17.5 f}{x^{1.36} \cdot \ln \left(h_{s}\right)},
$$

predicts tritium dose within a factor of 2 over the range of scenarios developed, within the known range of uncertainty of environmental tritium dose estimates. This concept is being carried forward to the development of a reduced model for particulate emissions from stacks at the SRS. 


\section{REFERENCES}

Bauer, L.R.; Hamby, D.M. Relative sensitivities of existing and novel model parameters in atmospheric tritium dose estimates. Radiation Protection Dosimetry. 37:253-260; 1991.

Bauer, L.R. Modeling chronic atmospheric releases at the SRS: Evaluation and verification of XOQDOQ. Westinghouse Savannah River Company. Aiken, SC: Report No. WSRC-RP91-320; 1991.

Box, G.E.P.; Hunter, W.G.; Hunter, J.S. Statistics for experimenters: An introduction to design, data analysis, and model building. John Wiley \& Sons. New York, NY; 1978.

Eckerman, K.F.; Congel, F.J.; Roecklin, A.K.; Pasciak, W.J. User's guide to GASPAR code. U.S. Nuclear Regulatory Commission. Washington, DC: Report No. NUREG/-0597; 1980.

Eimutis, E.C.; Konieck, M.G. Derivations of continuous functions for the lateral and vertical atmospheric dispersion coefficients. Atmospheric Environment. 6:859-863; 1972.

Hamby, D.M. Verification of the GASPAR dose assessment module used in MAXIGASP and POPGASP. Westinghouse Savannah River Company. Aiken, SC: Report No. WSRC-RP92-418; 1992.

Hamby, D.M. A probabilistic estimation of atmospheric tritium dose. Health Physics. 65:33-40; 1993.

Hamby, D.M. A comparison of sensitivity analysis techniques. Health Physics. 68:195-204; 1995.

Hamby, D.M.; Bauer, L.R. The vegetation-to-air concentration ratio in a specific activity

- atmospheric tritium model. Health Physics. 66:339-342; 1994.

International Commission on Radiological Protection. Limits for intakes of radionuclides by workers. New York, NY: Pergamon Press; ICRP Publication 30, Part 1; 1978.

Miller, C.W.; Havely L.M. A review of validation studies for the gaussian plume atmospheric dispersion model. Nuclear Safety. 28:522-531; 1987.

National Council on Radiation Protection and Measurements (NCRP). Screening models for releases of radionuclides to atmosphere, surface water, and ground. Washington, DC: NCRP Press; Report 123 I; 1996.

Pendergast, M.M. Power law profiles of mean winds and horizontal and vertical standard deviations of wind direction at the Savannah River Plant: Savannah River Laboratory Environmental Transport and Effects Research Annual Report. E.I. DuPont de Nemours. Savannah River Laboratory. Aiken, SC: Report No. DP-1455; 1976.

Sagendorf, J.F.; Goll, J.T.; Sandusky, W.F. XOQDOQ: Computer program for the meteorological evaluation of routine effluent releases at nuclear power stations. U.S. Nuclear Regulatory Commission. Washington, DC: Report No. NUREG/CR-2919; 1982.

Simpkins, A.A.; Hamby, D.M. Predicted versus measured tritium oxide concentrations at the Savannah River Site. Health Physics. 72:179-185; 1997. 
Stull, R.B. An introduction to boundary layer meteorology. Kluwer Academic Publishers. Boston, MA: pp. 376-379; 1988.

U.S. Department of Energy. Internal dose conversion factors for calculation of dose to the public. Washington, DC: Assistant Secretary for Environment, Safety and Health. Report No. DOE/EH-0071; 1988.

U.S. Environmental Protection Agency. Limiting values of radionuclide intake and air concentration and dose conversion factors for inhalation, submersion, and ingestion. Washington, DC: Federal Guidance Report No. 11. EPA-520/1-88-020; 1988.

U.S. Environmental Protection Agency. User's guide for CAP88-PC. Washington, DC: Report No. EPA-402-B-92-001; 1992.

U.S. Nuclear Regulatory Commission. Calculation of annual doses to man from routine releases of radioactive effluents for the purpose of evaluating compliance with 10 CFR Part 50, Appendix I. Washington, DC: U.S. Government Printing Office; U.S. NRC Regulatory Guide 1.109 Rev. 1; 1977a.

U.S. Nuclear Regulatory Commission. Methods for estimating atmospheric transport and dispersion of gaseous effluents in routine releases from light-water-cooled reactors. Washington, DC: U.S. Government Printing Office; U.S. NRC Regulatory Guide 1.111 Rev. 1; 1977b.

Westinghouse Savannah River Company (WSRC). Savannah River Site environmental report for 1996. Aiken, SC: Report No. WSRC-TR-97-0171; 1997. 


\section{FIGURE CAPTIONS}

Fig. 1. Influence of stack height and downwind distance on air concentration.

Fig. 2. Predicted vs. "observed" chronic atmospheric dose factor per unit curie release of tritium.

Fig. 3. Frequency distribution of fractional difference $(\mathrm{K}=1.9)$.

Fig. 4. Frequency distribution of fractional difference $(\mathrm{K}=2.1)$.

Fig. 5. Goodness of fit as a function of downwind distance.

Fig. 6. Goodness of fit as a function of wind-direction frequency.

Fig. 7. Goodness of fit as a function of stack height.

Fig. 8. Goodness of fit as a function of windspeed. 
Table 1. Parameter descriptions for the aggregated model of individual dose from tritium released to the atmosphere.

Frequency of winds toward sector $\mathbf{k}$

Percent water in vegetation

Ratio of plant tritium to atmospheric tritium

Tritium dose factor

Horizontal diffusion coefficient

Average wind speed

Stack-to-receptor distance

Average annual absolute humidity

Effective release height

Annual average breathing rate of adult male

Consumption rate of milk

Feed-to-milk transfer factor

Fodder ingestion rate (milk cattle)

Milk transport time (milking to consumption)

Consumption rate of beef

Feed-to-beef transfer factor

Fodder ingestion rate (beef cattle)

Beef transport time (slaughter to consumption)

Consumption rate of produce

Fraction of produce from home garden

Consumption rate of leafy vegetables

Fraction of leafy vegetables from home garden

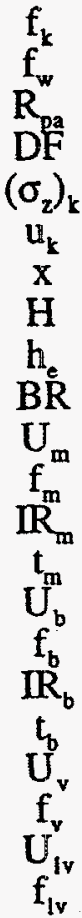


Table 2. Selected reduce model variants and their accuracy and precision measures. measure, $M_{a}$ measure, $M_{p} \quad$ Range

$\frac{K f}{\left(A x^{B}+C x\right)^{*} u_{k}} \cdot e^{-\frac{k_{j}^{2}}{2\left(A x^{3}+C\right)^{2}}}$

14.5

$0.345-0.58-0.97$

$\frac{K f}{\left(A x^{B}+C x\right) * u_{k}^{*} h_{s}}$

15.6

$0.352-0.64-1.45$

$\frac{K f}{\left(A x^{B}+C x\right)^{*} u_{k} * \ln \left(h_{s}\right)}$

11.1

$0.302-0.49-1.11$

$\frac{K f}{\left(A x^{B}+C x\right)^{*} u_{t}^{*} \ln \left(h_{s}\right)}$

9.1

0.276

$-0.45-0.83$

$\frac{K f}{\left(A x^{B}+C x\right)^{*} \ln \left(h_{s}\right)}$

9.1

0.276

$-0.48-0.86$

$\frac{K f}{A x^{B} * \ln \left(h_{s}\right)}$

$(K=1.9)$

9.2

0.282

$-0.47-0.89$

$\frac{K f}{A x^{B} * \ln \left(h_{s}\right)}$

$(\mathrm{K}=2.1)$

10.8

$0.311-0.42-1.09$ 


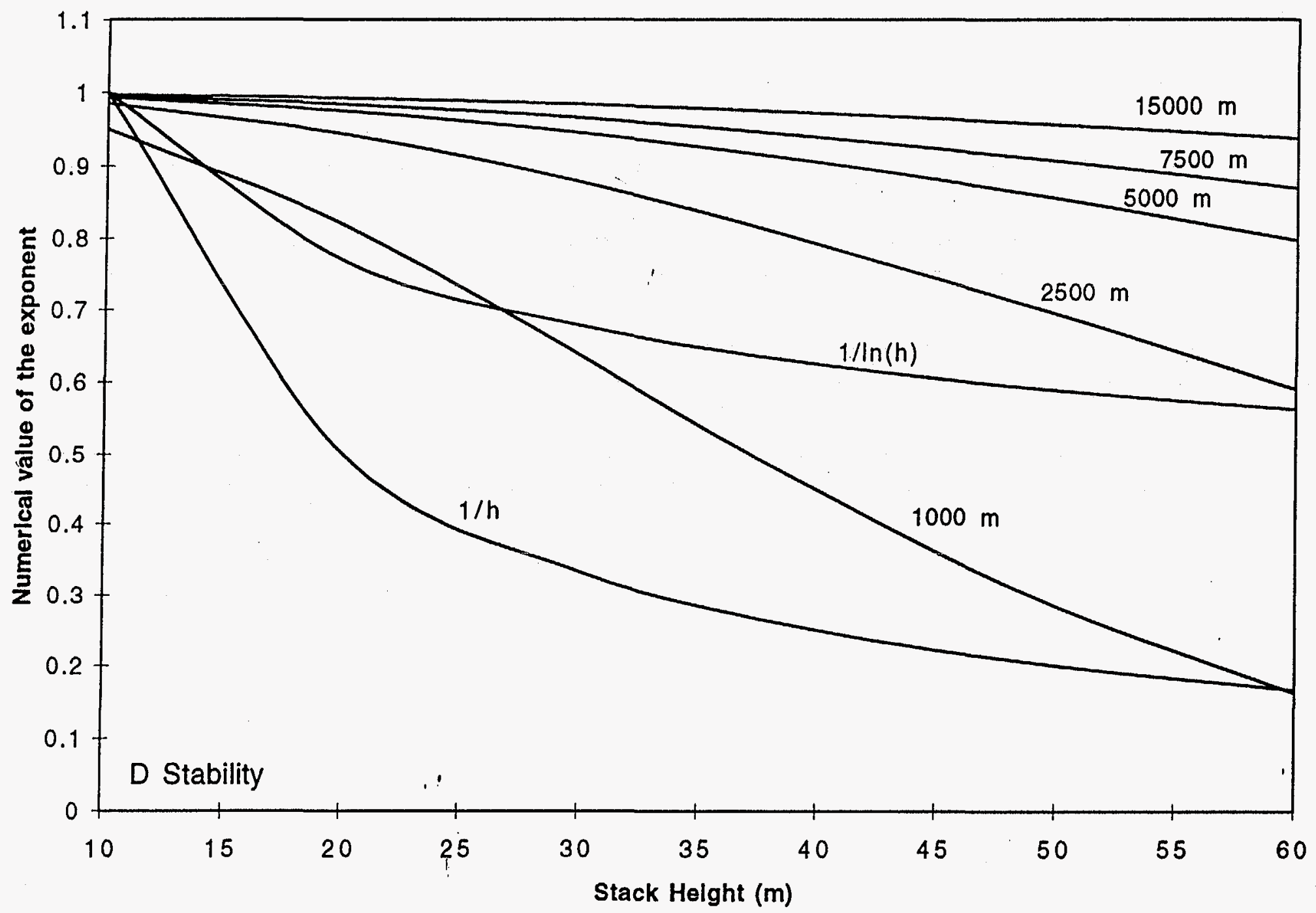




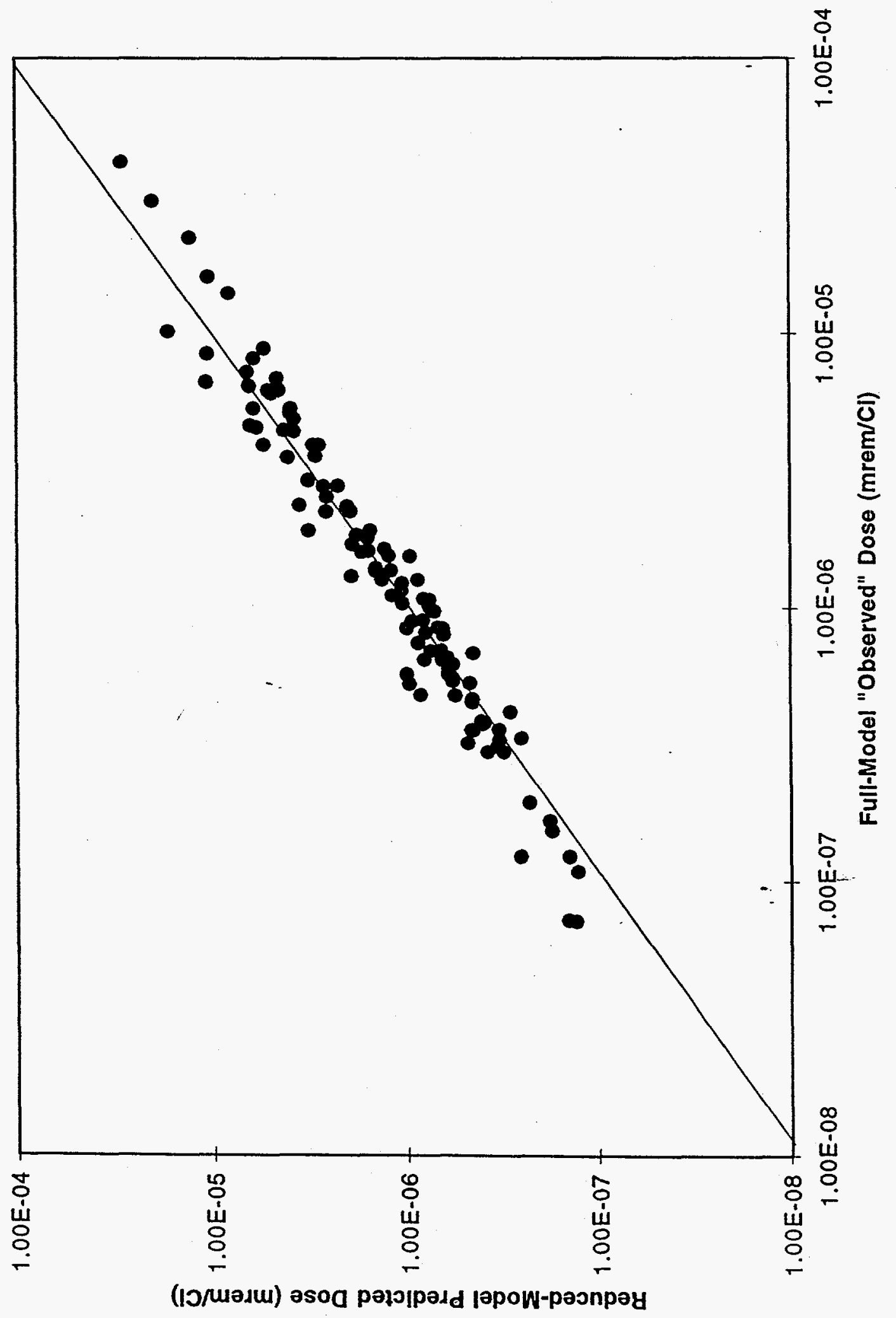




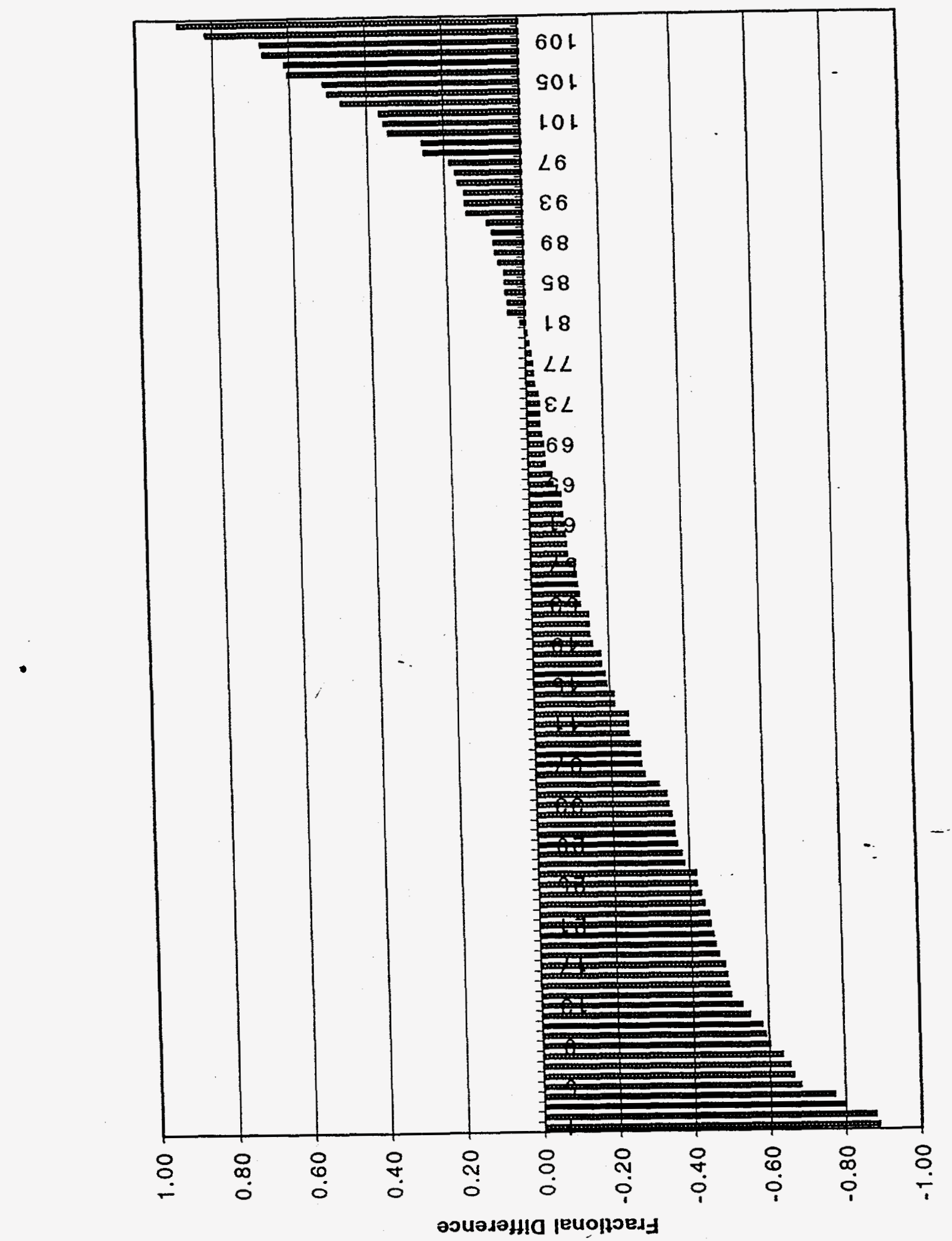




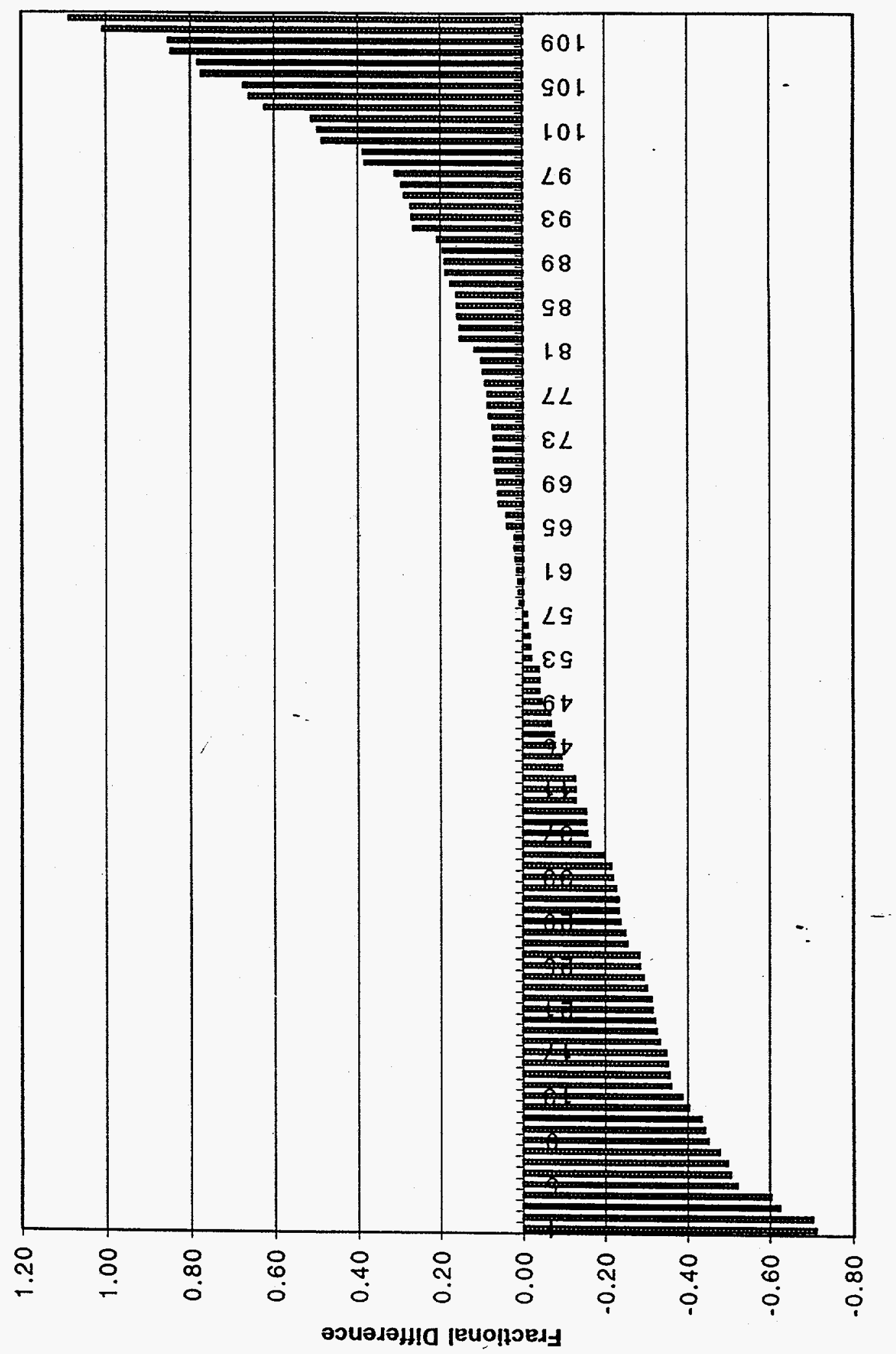




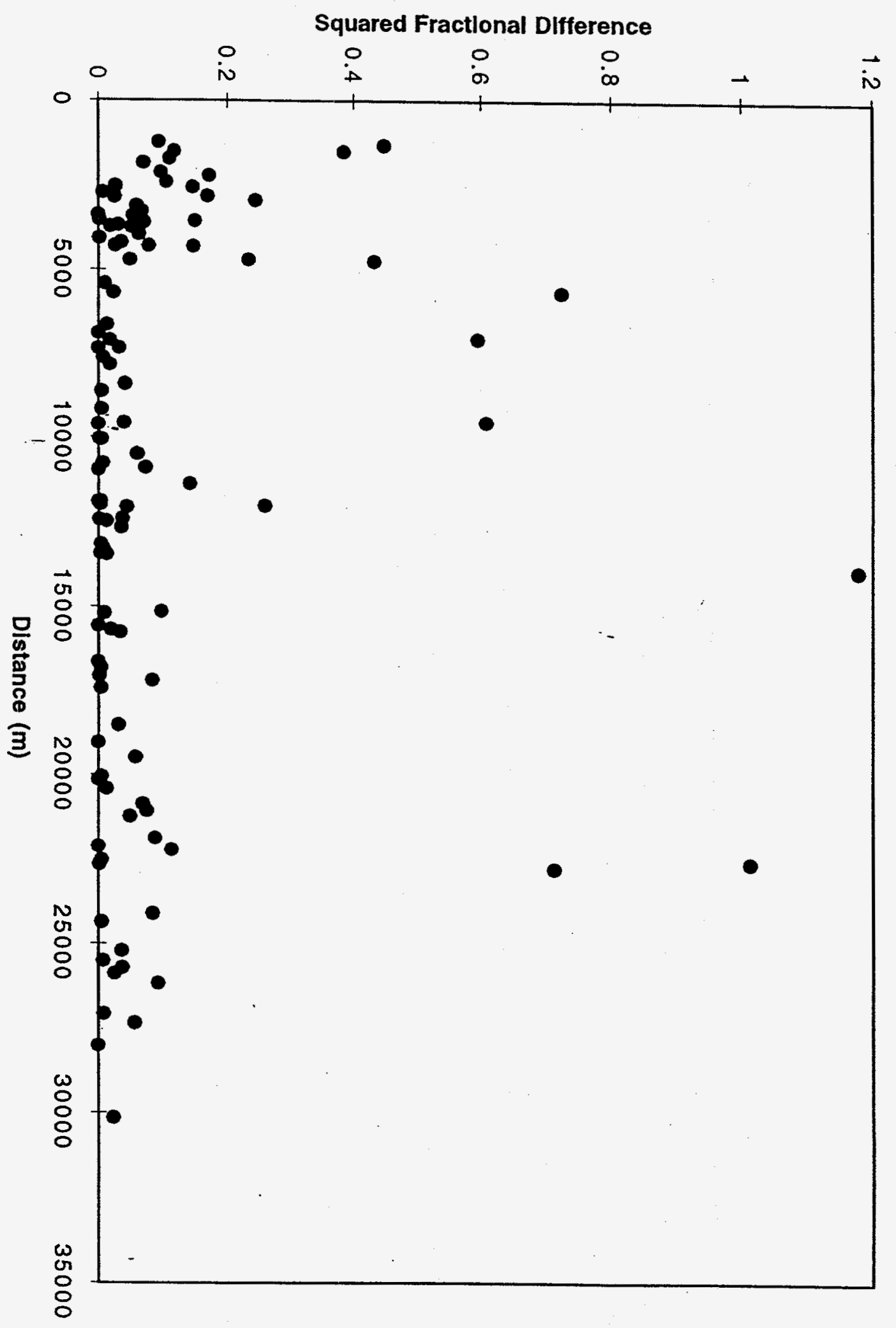




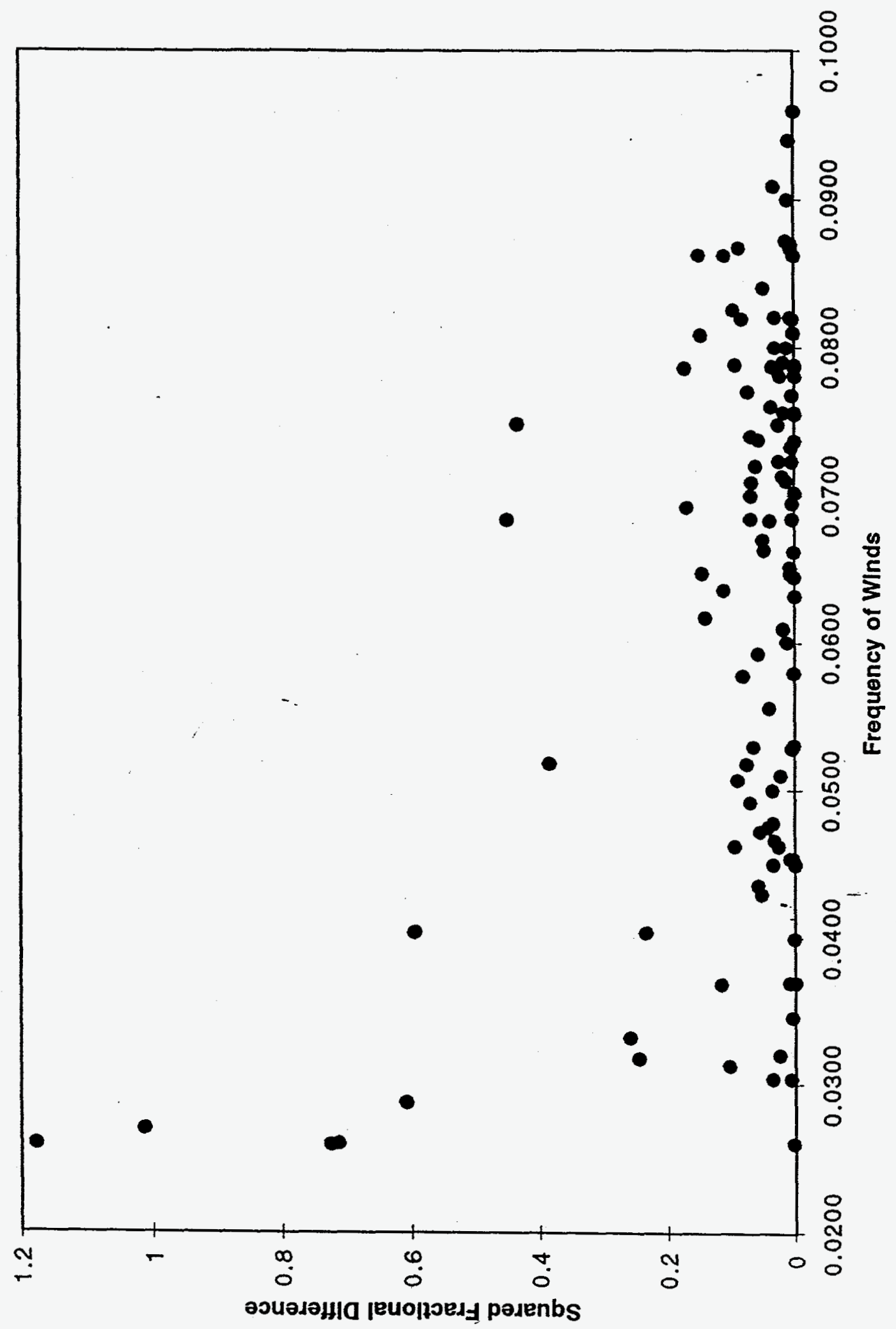




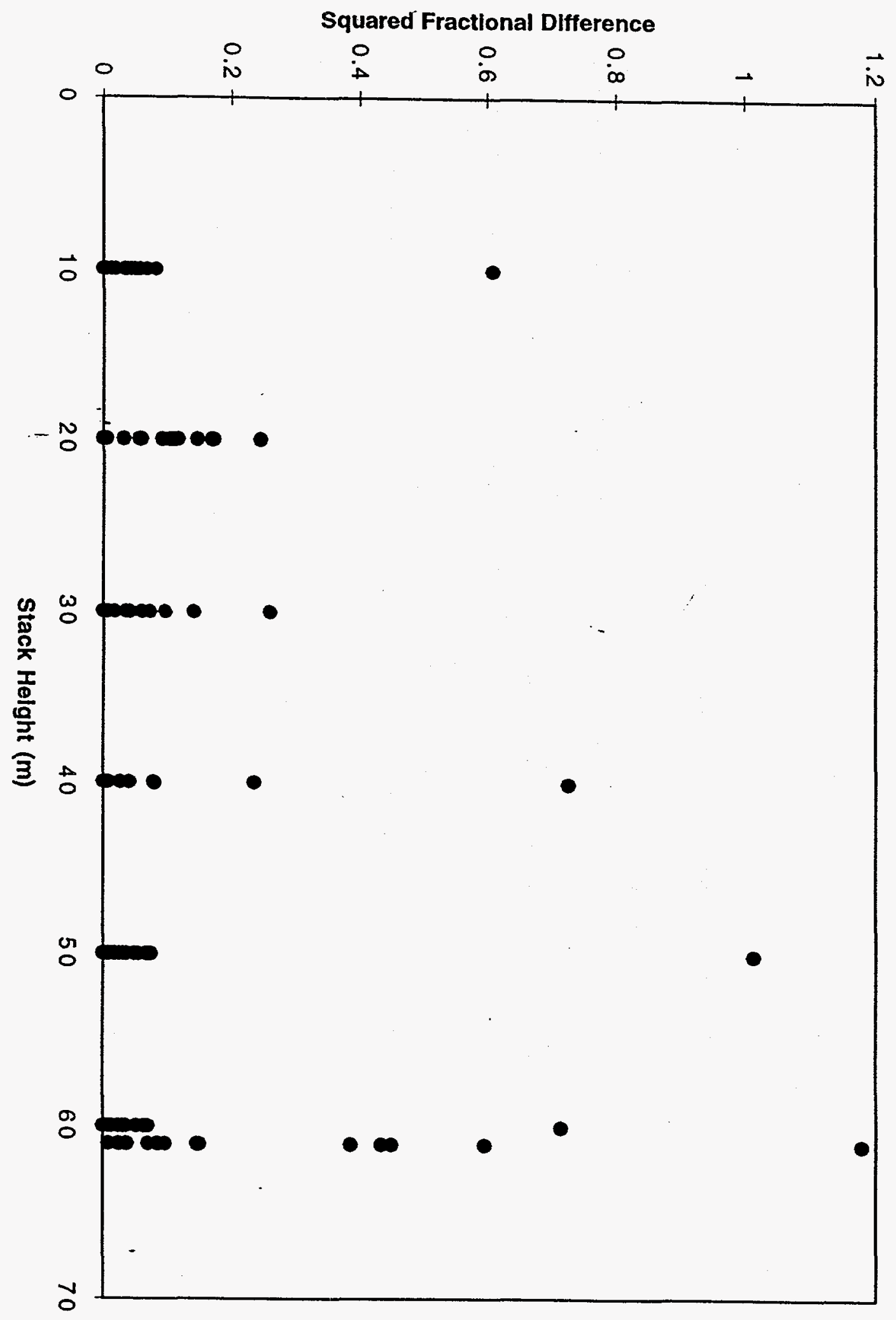




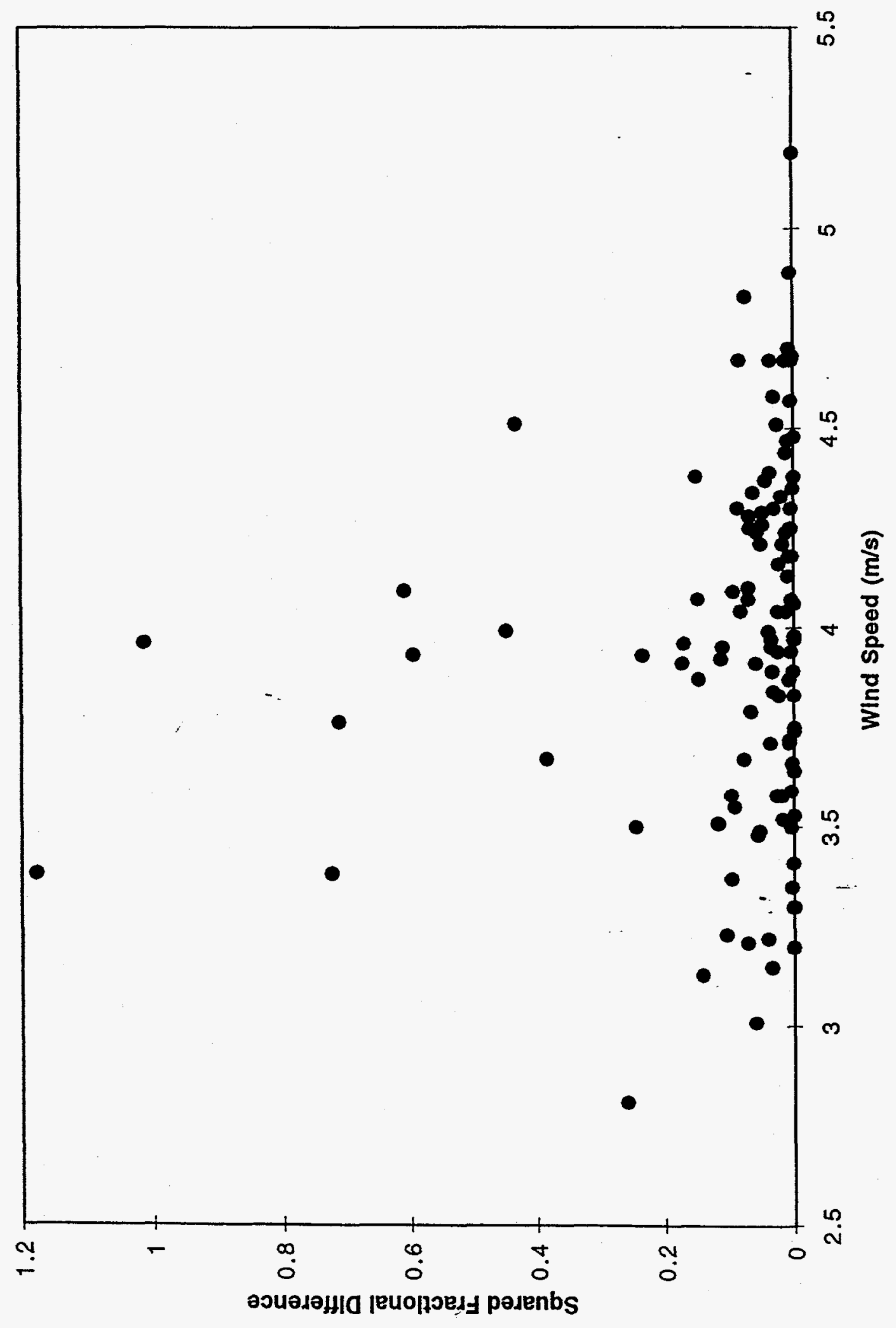

